Article

\title{
Improving the Sustainable Competitiveness of Service Quality within Air Cargo Terminals
}

\author{
Yi-Chung $\mathrm{Hu}^{1,2}{ }^{(\mathbb{D})}$, Ping-Chuan Lee ${ }^{2, *}$, Yuh-Shy Chuang ${ }^{3}$ and Yu-Jing Chiu ${ }^{2}$ \\ 1 College of Management \& College of Tourism, Fujian Agriculture and Forestry University, \\ Fuzhou 350002, China; ychu@cycu.edu.tw \\ 2 Department of Business Administration, Chung Yuan Christian University, Taoyuan City 32023, Taiwan; \\ yujing@cycu.edu.tw \\ 3 Department of International Business, Chien Hsin University, Taoyuan City 32097, Taiwan; \\ yschuang@uch.edu.tw \\ * Correspondence: g9804102@cycu.edu.tw
}

Received: 20 June 2018; Accepted: 30 June 2018; Published: 4 July 2018

\begin{abstract}
In Taiwan, the air cargo terminal business is a government franchise. Due to changing order and delivery modes, the volume of cargo exports has gradually decreased in recent years, generating increasing competitiveness within the air cargo terminal industry. Previous studies of air cargo terminals have largely focused on manpower supply planning and business performance. When a company pursues sustainable development and growth, it can improve the quality of the service provided, promote better customer satisfaction and enhance its competitiveness and customer loyalty in order to enjoy sustained development and higher profits. Having carried out a literature review, exploration and interviews with experts, this study develops a preliminary structure that is based on theory and practice and develops a framework for air cargo terminal service quality using the decision-making trial and evaluation laboratory (DEMATEL) method combined with the analytic network process (ANP). Eight key criteria are examined, namely, 'New facilities or high-tech equipment,' 'Professional spirit,' 'Security and safety,' 'Sense of trust,' 'Ability to handle unusual cargo,' 'Professional,' 'Standard operation processes,' and 'Customer equity.' The causality among each of these principles is also evaluated using the D-ANP questionnaire that was completed by 25 business forwarders. With respect to the quality of service demanded by forwarders, different strategies were drafted separately and provide a frame of reference for air cargo terminal operators.
\end{abstract}

Keywords: air cargo terminal; service quality; ANP; multiple criteria decision making; DEMATEL

\section{Introduction}

Owing to shorter product life cycles and rapid delivery, the demand for air cargo transportation has continued to increase over the past few years. According to Boeing's World Air Cargo Forecasting Report (WACF), the world's air cargo volume is expected to increase by an average of $4.2 \%$ per annum over the next 20 years and Asia will continue to retain its lead position with respect to the world's average annual increase in air cargo volume [1]. In light of intensified competition in the region, the International Air Transport Association (IATA) forecasts [2] that the profits of Asia Pacific Airlines will decrease by 15\% and the fierce price-oriented competition between airports is the subject of great concern.

From past exclusivity of the market to its more recent monopolization, Taiwan's air cargo terminals have also caused terminal operators to ignore the importance of service quality differentiation for a long time. In order to achieve sustainable management, a key aspect of competitiveness within the air cargo industry is quality of service [3]. Furthermore, the continuous improvement of service quality is an important issue for maintaining a competitive advantage. As such, upgrading services 
and outperforming competitors by employing innovative and diverse strategies can not only avoid price wars but strengthen customer loyalty. The importance of service quality is self-evident. The level of service quality has a direct positive effect on customer satisfaction and customer satisfaction also shows a direct positive association with the profitability of the company [4].

According to the definition outlined in clause 16, Article 2 of the Civil Aviation Law of Taiwan [5], the business of an air cargo terminal refers to "the business remunerated by providing customs, warehousing sites, equipment and services required for air import, export, transport, or transshipment cargo distribution and import and export of the airport-controlled area."

Historically, Taiwan's air cargo terminal operation was a state-owned industry. Today, it is a government franchise, regulated under the Civil Aviation Law. At present, there are six companies, namely, TACT Logistics (hereafter referred to as TACT, Taoyuan City, Taiwan) and EVA Air Cargo Co., Ltd. (hereafter referred to as EVA, Taoyuan City, Taiwan), Farglory Aviation Free Trade Zone Co., Ltd. (hereafter referred to as Farglory, Taoyuan, Taiwan), Everterminal Co., Ltd. (hereafter referred to as Everter, Taoyuan, Taiwan), UPS Taiwan Branch and the Taiwan branch of FedEx. As both foreign companies operate their own aircraft, their business model is not comparable to that of local companies. Therefore, this study focuses only on local companies. As the air cargo terminal must invest in a sizeable amount of land and equipment and must ensure that its location satisfies its operational scale, very few have invested in the industry, thus leading to the formation of an oligopoly market in Taiwan.

Figure 1 shows the import and export volume of Taiwan's air cargo terminals in the last decade, highlighting the increasingly fierce competition among air cargo terminal operations. As the volume of re-exports is primarily affected by the density of airliners, airlines enjoy greater dominance in negotiations. In addition, most companies that have aircraft tend to use their own assets to manage imported and re-exported goods. However, while imported and re-exported goods are not within the scope of this research, it is possible to observe free competition within open air cargo terminals during the last ten years. Export forwarders have more bargaining chips in terms of choice of air cargo terminals, the market for which is becoming increasingly competitive. Figure 1 illustrates changes in export volumes over the last decade. In the past, the total export volume of TACT, which was once the sole occupant of the market, has fallen by nearly $45 \%$. Moreover, the total export volume of EVA, which has similar conditions, has also declined by about $40 \%$. However, volume is intense. Improving the quality of service to meet customer needs and enhance customer loyalty has become a critical issue within the air cargo terminal industry.

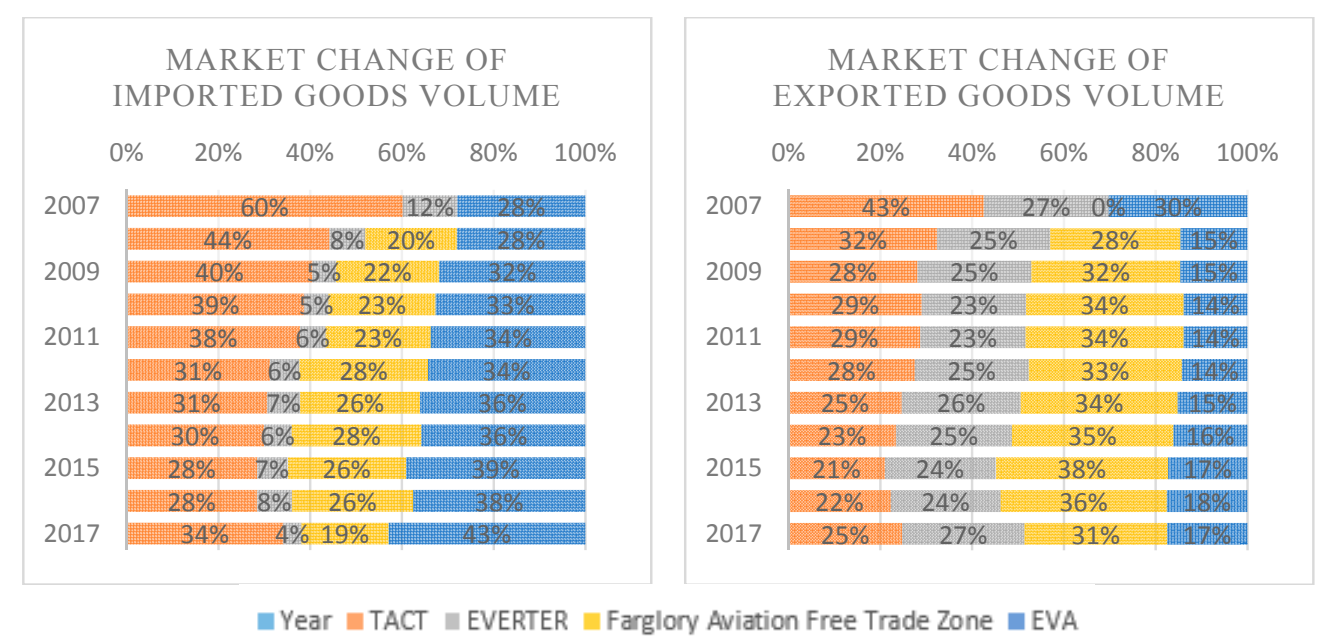

Figure 1. Market change of goods volume.

In the past, relevant research has investigated air cargo terminal operations by acknowledging the way in which quality of service impacts upon customer satisfaction and loyalty [6], influencing 
market segmentation of the cargo terminals [7], many of which focus on the manpower supply plan. However, previous studies have failed to address issues related to key criteria of the service quality of air cargo terminals and therefore cannot effectively reflect the forwarder's perception of the quality of service offered by air cargo terminals. In order to enhance the competitiveness of cargo terminals, this study focuses on key factors that directly relate to the service quality of Taiwan's air cargo terminal operations and furthermore evaluates the operational performance of such terminals.

\section{Literature Review}

\subsection{Air Cargo Forwarder Industry in Taiwan}

The freight forwarder industry is a freight brokerage agency that acts as an intermediary between the shipper and the carrier, handling import and export customs declaration documents, cargo insurance and packaging and warehousing services to meet various customer requirements. The principal business of general air cargo forwarders includes import and export freight forwarding as well as transshipment freight transportation that focuses on managing air cargo transportation.

At present, there are approximately 1000 freight forwarders operating in Taiwan [3], most of which are small and medium-sized enterprises. About $80 \%$ of the business owner's capital is under NT $\$ 10$ million. Therefore, most of Taiwan's air cargo exports are contracted by larger industry players. In general, more than $50 \%$ of the total export volume of all forwarders can be attributed to the top 25 air forwarders. This study focuses on the top 25 forwarders in terms of export volumes.

\subsection{Service Quality}

Services are activities that are performed to meet the needs of consumers or customers. Parasurman, Zeithaml and Berry et al. [8] studied and developed PZB service quality models, identifying five specific gaps that affect service quality, which is subdivided according to 10 dimensions and includes 97 quality measurement items. In 1988, the SERVQUAL scale [4] was developed, reducing the number of quality-specific dimensions to five, namely, "tangibles", "reliability", "responsiveness", "assurance", and "empathy". This study adopts a research framework that is based on the five aspects outlined in this model.

Most research that has studied the quality of service provided by the air cargo industry has concentrated on forwarders or air cargo logistics providers. However, as few studies have examined the key factors that affect the quality of service offered by air cargo terminals and the mutual influences found between them, the present research focuses on addressing these issues. This study carried out a literature review and interviews with two high-level executives who are experienced in the operation of air cargo terminals. Twenty-one criteria were evaluated and a preliminary framework was developed according to the dimensions outlined in terms of quality-specific aspects and criteria, as shown in Table 1.

Table 1. Preliminary aspects and criteria for the study.

\begin{tabular}{ccc}
\hline Aspects & Criteria & References \\
\hline \multirow{3}{*}{ Tangibles } & New facilities or high-tech equipment & {$[6,9-11]$} \\
& Geographical location & {$[6,7,9,12,13]$} \\
& Cargo tracking & {$[7,11-14]$} \\
& Customer service area & {$[12]$} \\
Website & {$[12,13]$} \\
\hline Reliability & To perform the contract & {$[6,7,9,11,14-16]$} \\
& Professional attitude & {$[6,9,11-14,17,18]$} \\
& Security and safety & {$[7,11,12,14,16-18]$} \\
& Cargo documents & {$[7,15,17]$} \\
& Reputation and corporate image & {$[7,11,12,19,20]$} \\
& Sense of trust & {$[6,9,12,20]$} \\
\hline
\end{tabular}


Table 1. Cont.

\begin{tabular}{ccc}
\hline Aspects & Criteria & References \\
\hline \multirow{2}{*}{ Responsiveness } & Service attitude & {$[6,9,13,14]$} \\
& Ability to handle unusual cargo & {$[9,10,13,15]$} \\
\hline \multirow{2}{*}{ Assurance } & Compensation & {$[9,10,13,15]$} \\
& Professional & {$[6,7,9,11,14-17]$} \\
& Standard Operation Process & {$[7,14]$} \\
\hline \multirow{2}{*}{ Empathy } & Convenience & {$[6,9,13,19]$} \\
& Customer equity & {$[6,9]$} \\
& Customization & {$[13,14,17,18]$} \\
& Price elasticity & {$[11,13,14,16,18-20]$} \\
\hline
\end{tabular}

\section{Research Methods}

\subsection{Delphi Method}

This study utilized the Delphi method of long-term prediction technology [18] developed by the Rand (Rand Corporation) Company in the 1950s to establish the key factors for the service quality of air cargo terminals. This method reflects the structural group communication process, the main objective of which is to reach a consensus among a group of reliable experts [19]. Outstanding issues that required resolution are delivered to each expert who provides a written discussion. The confidentiality of the identity of experts is ensured. Having collected all expert opinions, which are provided to all experts in order to assist their understanding of differences among the expert group, a general opinion is ultimately formed. Following the repetition of a similar process, a consensus is eventually reached to resolve complex issues.

Nine experts, selected to form a group of experts, were invited to participate in the revised version of the original prototype study design. Relevant background information is shown in Table 2.

Table 2. Background of Experts Interviewed with the Delphi Method.

\begin{tabular}{cccc}
\hline Expert Code & Service Unit & Title & Years of Experience \\
\hline Expert A & Air cargo terminal distribution industry & Manager & 15-25 years \\
Expert B & Air cargo terminal distribution industry & Manager & 15-25 years \\
Expert C & Air cargo terminal distribution industry & Manager & 15-25 years \\
Expert D & Air cargo terminal distribution industry & Manager & 15-25 years \\
Expert E & Air cargo terminal distribution industry & Manager & 15-25 years \\
Expert F & Air cargo terminal distribution industry & Manager & 15-25 years \\
Expert G & Airline Freight Dept. & Manager & 15-25 years \\
Expert H & $\begin{array}{c}\text { Qualified senior manager of forwarders } \\
\text { who is presently a scholar in relevant areas } \\
\text { Qualified senior manager of forwarders } \\
\text { Expert I }\end{array}$ & Teacher & 15-25 years \\
& Tho is presently a scholar in relevant areas & Teacher & 20-30 years \\
\hline
\end{tabular}

\subsection{DEMATEL-Based ANP (DANP)}

In 1996, Saaty proposed the Analytic Network Process (ANP) to solve the dependency and feedback relationship between the standards [20]. ANP offers a solution to the nonlinear problem and is a decision method that can be used when there is a correlation among various factors. As such, it is a multi-criteria evaluation method that can systemize a slightly complex problem. The result of the evaluative analysis can be provided to the decision-maker to aid decision-making. In the past, ANP has been employed as a research method to address highly diverse subjects. The method is often used for the selection of management decisions, supplier selection, process improvement, choice of decision plans and so forth. From 1972 to 1976, the Battelle Association improved upon the 
Decision-Making Trial and Evaluation Laboratory (DEMATEL) methodology. Proposed in Geneva in 1971, the DEMATEL method was used to solve complex analyses of various human and technological problems as well as to resolve associated problem groups (i.e., such as environmental protection, energy, ethnic issues, etc.) to assist in studies and discussions. The D-ANP (DEMATEL-based ANP) used in this study is a hybrid MCDM model, generated by combining the Network Analysis Process method (ANP) and the Decision-Making Trial and Evaluation Laboratory methodology (DEMATEL).

By harnessing the convenience and practicality offered by the D-ANP in operation and by situating the analysis within the D-ANP operational framework proposed by Hu et al. [21], the data analysis and scenario selection model was created and is shown in Figure 2. The analytical model of this operational architecture emphasizes the use of the Borda Method, which was developed by Borda [22]. The key factors are determined by degree of importance (i.e., centrality), which is obtained using DEMATEL and the weights attributed to criteria using the ANP. The total impact matrix determines the impact of key factors. Only key factors are considered with respect to the drawing of causality diagrams, thereby avoiding interference from non-critical factors when determining causality.

i. Determining the Total Influence Matrix.

First, the degree of influence exerted by one criteria onto another is assigned numerically as follows: 1 (no effect); 2 (weak effect); 3 (local effect); 4 (major effect); and 5 (massive effect), each of which are indicated in performance values. Second, for each pair of criteria generated from the questionnaire, a direct influence matrix $\boldsymbol{Z}$ was constructed using their associated degree of effect. $z i j$ indicates the extent of the influence of criterion $i$ on criterion $j$. All diagonal attributes are set at zero:

$$
\mathbf{Z}=\left[\begin{array}{cccc}
z_{11} & z_{12} & \ldots & z_{1 n} \\
z_{21} & z_{22} & \ldots & z_{2 n} \\
\vdots & \vdots & \vdots & \vdots \\
z_{n 1} & z_{n 2} & \ldots & z_{n n}
\end{array}\right]
$$

The direct influence matrix $\boldsymbol{Z}$ was normalized to generate a normalized direct influence matrix $\boldsymbol{X}$ upon calculation.

$$
\lambda=\frac{1}{\max _{1 \leq i \leq n} \sum_{j=1}^{n} z_{i j}}(i, j=1,2, \ldots, n) X=\lambda \cdot \boldsymbol{Z}
$$

When the direct influence matrix was normalized, the formula $\boldsymbol{T}=\boldsymbol{X}(\mathrm{I}-\mathrm{X})^{-1}$ was used to show the total influence matrix $T$. At this stage, $O$ indicates the zero matrix, while the identity matrix is denoted by I:

$$
\begin{gathered}
\lim _{\mathrm{K} \rightarrow \infty} X^{\mathrm{k}}=0 \\
\boldsymbol{T}=\lim _{\mathrm{X} \rightarrow \infty}\left(X+X^{2}+\cdots+X^{k}\right)=X(I-X)^{-1}
\end{gathered}
$$

As an unweighted supermatrix, the total influence matrix $T$ was used to normalize the total influence matrix to obtain the weighted matrix $\boldsymbol{W}$ for the ANP. The limiting supermatrix $\boldsymbol{W}^{*}$ and the global weight of all attributes are obtained, as $W$ was multiplied by itself repeatedly before convergence. The DANP is briefly depicted in Figure 2.

Below, a simple example is used to illustrate the above-mentioned operation with respect to factors A, B, C, D and E for a decision problem. Let a direct influence matrix $\mathbf{Z}$ be obtained as follows:

$$
\boldsymbol{Z}=\frac{\mathrm{B}}{\mathrm{B}} \mathrm{C}\left[\begin{array}{ccccc}
\mathrm{A} & \mathrm{B} & \mathrm{C} & \mathrm{D} & \mathrm{E} \\
0 & 2 & 1 & 1 & 1 \\
2 & 0 & 2 & 1 & 1 \\
\mathrm{D} & 1 & 0 & 1 & 1 \\
2 & 1 & 2 & 0 & 1 \\
2 & 2 & 2 & 2 & 0
\end{array}\right]
$$


This matrix was subsequently normalized to obtain the normalized relation matrix $X$.

$$
\begin{aligned}
& \boldsymbol{T}=\mathrm{A} \text { C }\left[\begin{array}{ccccc|c}
\mathrm{A} & \mathrm{B} & \mathrm{C} & \mathrm{D} & \mathrm{E} & d \\
2.151 & 2.201 & 2.217 & 2.092 & 2.079 & 10.738 \\
2.450 & 2.094 & 2.322 & 2.171 & 2.147 & 11.184 \\
2.451 & 2.274 & 2.122 & 2.182 & 2.158 & 11.188 \\
2.401 & 2.247 & 2.285 & 1.977 & 2.133 & 11.043 \\
2.526 & 2.348 & 2.403 & 2.289 & 2.063 & 11.665
\end{array}\right. \\
& \begin{array}{llllll}
r & 11.979 & 11.200 & 11.348 & 10.711 & 10.580
\end{array}
\end{aligned}
$$

Then the total influence matrix $T$ was calculated using $T=X(I-X)^{-1}$.

Causes and effect can be derived from $T$, each row was summed to obtain the value denoted by $d$ and each column of the total influence matrix was summed to obtain the value denoted by $r$. Then $d+r$ is the prominence and shows the relative importance of the corresponding facto; and $d-r$ is the relation, where a positive relation means the corresponding factor tends to affect other elements actively.

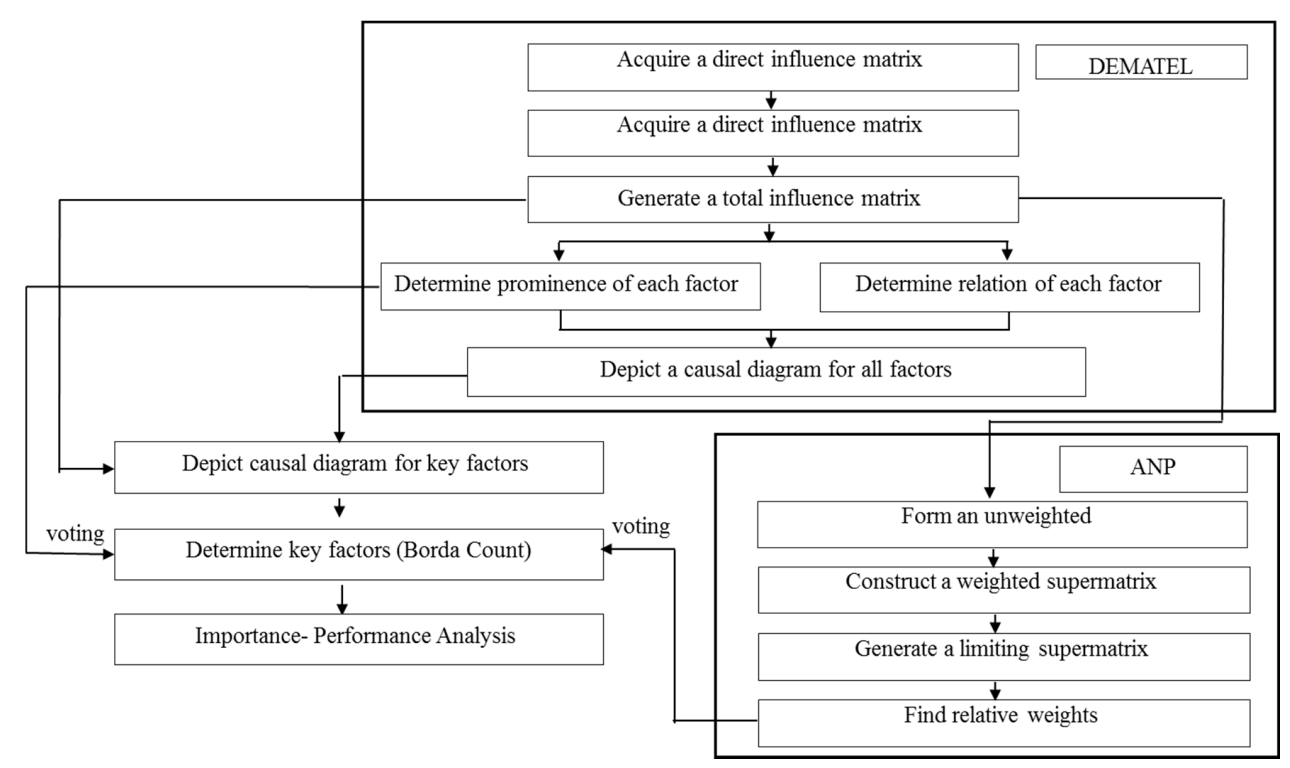

Figure 2. Proposed DANP framework.

\subsection{Importance-Performance Analysis}

As resources of the company are limited, they must be assigned to the most strategically favorable areas. Importance-Performance Analysis (IPA), proposed by Martilla and James [23], is the most widely accepted method to solve the prioritization and allocation of resources within an enterprise. As shown in Figure 3 below, each quadrant in the IPA method is divided in terms of each criteria's importance (vertical axis) and performance value (horizontal axis), thus producing four quadrants, namely, 'concentrate here,' 'low priority,' 'keep up the good work' and 'possible overkill.' If the key criteria are located within the 'concentrate here' quadrant, it is advisable that the company make amendments to this key criterion. The results of the study are important for improving the service quality of air cargo terminals. 


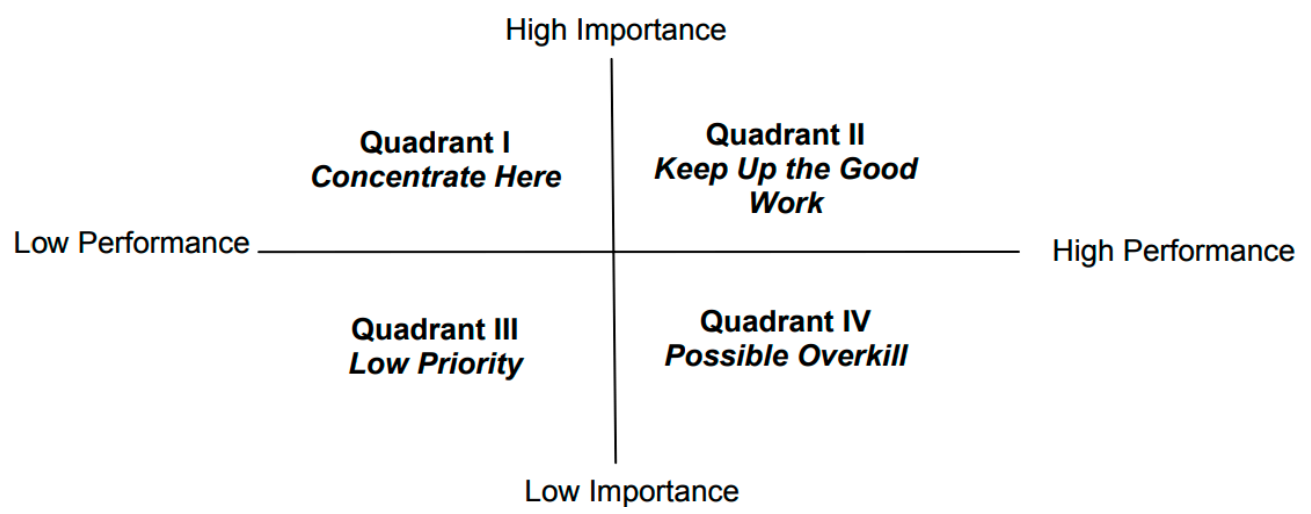

Figure 3. Importance-performance analysis.

\section{Empirical Study}

\subsection{Establish an Evaluation Hierarchy}

Five evaluation aspects and 18 evaluation criteria were identified from the recommendations of the expert group with respect to the aspects and criteria.

\subsection{Delphi Method Questionnaire Results and Expert Suggestions}

This study designed the questionnaire by employing the Delphi method and requested expert groups to assign scores according to whether or not the criteria were included in the study framework. The scores were adjusted using the maximum average score and Consensus Deviation Index (CDI) results were used to verify whether a consensus was reached among the nine expert groups. In this study, the threshold for the consensus difference was set at CDI $\leq 0.1$. Two rounds of expert questionnaires were conducted. Expert groups reached a consensus on the need for evaluation criteria. Following discussion with the group of experts, it was agreed that an 80-point average should be used as the threshold for the deletion of evaluation criteria, that is, a criterion with an average score of less than 80 points would be deemed redundant and then deleted. Finally, a total of 17 evaluation criteria were retained and included in the formal research framework, which is shown in Table 3.

Table 3. Preliminary aspects and criteria for the study.

\begin{tabular}{|c|c|c|}
\hline Aspects & Criteria & Descriptions \\
\hline \multirow{3}{*}{ Tangibles $(A)$} & New facilities or high-tech equipment (A1) & $\begin{array}{l}\text { The company has a modern air cargo terminals fully equipped with the } \\
\text { hardware, software, cold chain and other ancillary equipment needed to } \\
\text { handle the goods. }\end{array}$ \\
\hline & Geographical location (A2) & $\begin{array}{l}\text { The operating space is of an adequate size. The location of the warehouse, } \\
\text { the transportation network near the warehouse and the line layout of the air } \\
\text { cargo terminals are sufficient to meet demands. }\end{array}$ \\
\hline & Cargo information platform (A3) & $\begin{array}{l}\text { Cargo checking, equipment completeness and cargo tracking systems at the } \\
\text { terminals are sufficient to meet demands. }\end{array}$ \\
\hline \multirow{5}{*}{ Reliability $(B)$} & Ability to fulfil contracts (B1) & Terminals can fulfil promises and goods on time. \\
\hline & Professional spirit (B2) & $\begin{array}{l}\text { The service personnel are professional, devoted, passionate, exertive, } \\
\text { with professional ethics, professional conduct and dedication. }\end{array}$ \\
\hline & Security and safety (B3) & $\begin{array}{l}\text { The company has in place suitable safety and security procedures, resulting } \\
\text { in low rates of damage and loss. }\end{array}$ \\
\hline & Cargo documents (B4) & $\begin{array}{l}\text { EDI (Electronic Data Interchange) transmits correctly and correctly handles } \\
\text { various transportation documents. }\end{array}$ \\
\hline & Sense of trust (B5) & Service personnel give customers a sense of trust and clearly explain services. \\
\hline
\end{tabular}


Table 3. Cont

\begin{tabular}{|c|c|c|}
\hline Aspects & Criteria & Descriptions \\
\hline \multirow[t]{2}{*}{ Responsiveness $(C)$} & Service attitude (C1) & $\begin{array}{l}\text { Service personnel provide customers with the information they need. } \\
\text { Smooth and real-time communication channels are open. Customer inquiries } \\
\text { (such as trade inquiry) are answered in real time. Documents are rapid } \\
\text { processed and warehousing operators inform customers of the expected } \\
\text { delivery time after completing the deconsolidation of goods. The customer is } \\
\text { notified when the goods have been delivered. Service staff are willing to help } \\
\text { the customer to solve problems. }\end{array}$ \\
\hline & Ability to handle unusual cargo (C2) & $\begin{array}{l}\text { Issues with respect to unusual cargoes are handled quickly, with good } \\
\text { responsiveness and reasonableness. }\end{array}$ \\
\hline \multirow{3}{*}{ Assurance $(D)$} & Damage compensation (D1) & Processing of cargo damage compensation is efficient. \\
\hline & Professional (D2) & $\begin{array}{l}\text { Air cargo terminal SGS, BV and ISO standards are used, to ensure air cargo is } \\
\text { handled safely. The company works to achieve staff resilience, improve } \\
\text { professional knowledge, provide professional air cargo terminals } \\
\text { management staff and improve storage-related consulting capabilities. }\end{array}$ \\
\hline & Standard operation processes (D3) & $\begin{array}{l}\text { The loading and unloading of goods is performed in accordance with } \\
\text { standard operating procedures, operations within the air cargo terminals are } \\
\text { efficient and goods are properly handled. }\end{array}$ \\
\hline \multirow{4}{*}{ Empathy $(E)$} & Customer equity (E1) & Air cargo terminal staff value customer rights. \\
\hline & Customization (E2) & $\begin{array}{l}\text { Provide customized services, logistics processing services (such as labeling, } \\
\text { carton packaging), logistics value-added services and consolidation services. }\end{array}$ \\
\hline & Price (E3) & $\begin{array}{l}\text { Complete operating fee schedules and flexible payment options are available } \\
\text { to customers. }\end{array}$ \\
\hline & Business hours (E4) & Provide extra overtime services and flexible booking times. \\
\hline
\end{tabular}

\subsection{Criteria Importance Analysis}

Criteria Importance Analysis. By using (1), (2) and (3), the prominence and relation of each criterion is concluded in Table 4 while the cause/effect properties of twelve criteria is summarized in Table 5.

Table 4. Prominence and relation of each criterion.

\begin{tabular}{ccccc}
\hline Criteria & $\mathbf{d}$ & $\mathbf{r}$ & $\mathbf{d}+\mathbf{r}$ & $\mathbf{d}-\mathbf{r}$ \\
\hline A1 & 10.9230 & 10.7194 & 21.6424 & 0.2036 \\
A2 & 8.2980 & 7.1679 & 15.4660 & 1.1301 \\
A3 & 10.3368 & 10.2416 & 20.5783 & 0.0952 \\
B1 & 10.2471 & 10.5118 & 20.7589 & -0.2647 \\
B2 & 10.6197 & 9.8995 & 20.5192 & 0.7202 \\
B3 & 10.4727 & 10.8878 & 21.3605 & -0.4150 \\
B4 & 6.5309 & 9.0400 & 15.5708 & -2.5091 \\
B5 & 10.2157 & 11.0237 & 21.2394 & -0.8080 \\
C1 & 10.3426 & 10.1752 & 20.5178 & 0.1674 \\
C2 & 10.4182 & 10.5737 & 20.9919 & -0.1555 \\
D1 & 10.3464 & 10.2485 & 20.5950 & 0.0979 \\
D2 & 10.8462 & 10.3364 & 21.1825 & 0.5098 \\
D3 & 10.6969 & 10.4072 & 21.1040 & 0.2897 \\
E1 & 10.5840 & 10.6599 & 21.2439 & -0.0759 \\
E2 & 9.9858 & 9.5785 & 19.5643 & 0.4073 \\
E3 & 9.6711 & 9.2127 & 18.8838 & 0.4584 \\
E4 & 9.1855 & 9.0369 & 18.2223 & 0.1486 \\
\hline
\end{tabular}

Table 5. Cause/effect properties of criteria.

\begin{tabular}{cl}
\hline Cause/Effect & \multicolumn{1}{c}{ Criteria } \\
\hline Cause & New facilities or high-tech equipment (A1), Professional (D2), Standard operation processes (D3) \\
\hline \multirow{2}{*}{ Effect } & $\begin{array}{l}\text { Professional spirit (B2), Security and safety (B3), Sense of trust (B5), Ability to handle unusual cargo } \\
\text { (C2), Customer equity (E1) }\end{array}$ \\
\hline
\end{tabular}

Table 6 demonstrates the overall rankings for criteria by arranging the sum of rankings of each criterion in ascending order. 
Table 6. The overall ranking for criteria.

\begin{tabular}{ccccc}
\hline Criteria & DEMATEL & DANP & Sum of Rankings & Overall Rankings \\
\hline A1 & 1 & 1 & 2 & 1 \\
A2 & 17 & 16 & 33 & 16 \\
A3 & 10 & 10 & 20 & 11 \\
B1 & 8 & 11 & 19 & 10 \\
B2 & 11 & 4 & 15 & 7 \\
B3 & 2 & 6 & 8 & 3 \\
B4 & 16 & 17 & 33 & 16 \\
B5 & 4 & 12 & 16 & 8 \\
C1 & 12 & 9 & 21 & 12 \\
C2 & 7 & 7 & 14 & 6 \\
D1 & 9 & 8 & 17 & 9 \\
D2 & 5 & 2 & 7 & 2 \\
D3 & 6 & 3 & 9 & 5 \\
E1 & 3 & 5 & 8 & 3 \\
E2 & 13 & 13 & 26 & 13 \\
E3 & 14 & 14 & 28 & 15 \\
E4 & 15 & 15 & 30 & \\
\hline
\end{tabular}

Based on the overall ranking list, key criteria are chosen as New facilities or high-tech equipment (A1), Professional Spirit (B2), Security and safety (B3), Sense of trust (B5), Ability to handle unusual cargo (C2), Professional (D2), Standard Operation Process (D3) and Customer equity (E1).

\subsection{Importance-Performance Analysis}

The relationship between rating and performance was also provided to criteria and is shown in Table 7.

Table 7. Cause/effect properties of criteria.

\begin{tabular}{cccccc}
\hline Rating & $\mathbf{1}$ & $\mathbf{2}$ & $\mathbf{3}$ & $\mathbf{4}$ & $\mathbf{5}$ \\
\hline Performance & Very dissatisfied & Dissatisfied & Ordinary & Satisfied & Very satisfied \\
\hline
\end{tabular}

Table 8 shows the average values for the performance of 26 cargo forwarding managers with respect to 17 criteria. The threshold value of 3.61 was agreed upon by all nine experts in order to identify criteria with acceptable $(\geq 3.61)$ or unacceptable $(<3.61)$ performance values from a total of 17 criteria. IPA is used to identify key criteria that require more attention.

Table 8. Performance assessment of 17 criteria.

\begin{tabular}{cccccc}
\hline Criteria & Air Cargo Terminal 1 & Air Cargo Terminal 2 & Air Cargo Terminal 3 & Air Cargo Terminal 4 & Average \\
\hline A1 & 3.3077 & 3.3462 & 3.7308 & 4.0000 & 3.5962 \\
A2 & 4.6154 & 2.8462 & 4.4615 & 3.5769 & 3.8750 \\
A3 & 3.6538 & 3.6538 & 3.9615 & 3.7692 & 3.7596 \\
B1 & 3.5385 & 3.6154 & 3.6154 & 3.5385 & 3.5769 \\
B2 & 3.5769 & 3.8077 & 3.5769 & 3.5769 & 3.6346 \\
B3 & 3.5769 & 3.8846 & 3.9615 & 3.8077 & 3.8077 \\
B4 & 3.6154 & 3.8077 & 3.8077 & 3.5385 & 3.6923 \\
B5 & 3.5385 & 4.1154 & 3.8462 & 3.6923 & 3.7981 \\
C1 & 3.4615 & 4.0769 & 3.5000 & 3.7692 & 3.7019 \\
C2 & 3.2692 & 3.6154 & 3.4615 & 3.5000 & 3.4615 \\
D1 & 3.3462 & 3.6923 & 3.4231 & 3.4615 & 3.4808 \\
D2 & 3.6923 & 3.9615 & 3.8077 & 3.6923 & 3.7885 \\
D3 & 3.8077 & 3.8846 & 3.7692 & 4.0000 & 3.8654 \\
E1 & 3.3462 & 3.6154 & 3.5769 & 3.5385 & 3.5192 \\
E2 & 3.1538 & 3.8077 & 3.3077 & 3.4231 & 3.4231 \\
E3 & 2.9615 & 3.7692 & 3.2692 & 3.3846 & 3.3462 \\
E4 & 3.6923 & 3.8077 & 3.6538 & 3.6538 & 3.7019 \\
\hline
\end{tabular}


As shown in Figure 4, New facilities or high-tech equipment (A1), Customer equity (E1), Ability to handle unusual cargo (C2), Professional spirit (B2), Professional (D2) and Security and safety (B3) appear in the upper right grid. All of these key factors are concentrated within this grid in order to ensure the optimal performance of air cargo terminals.

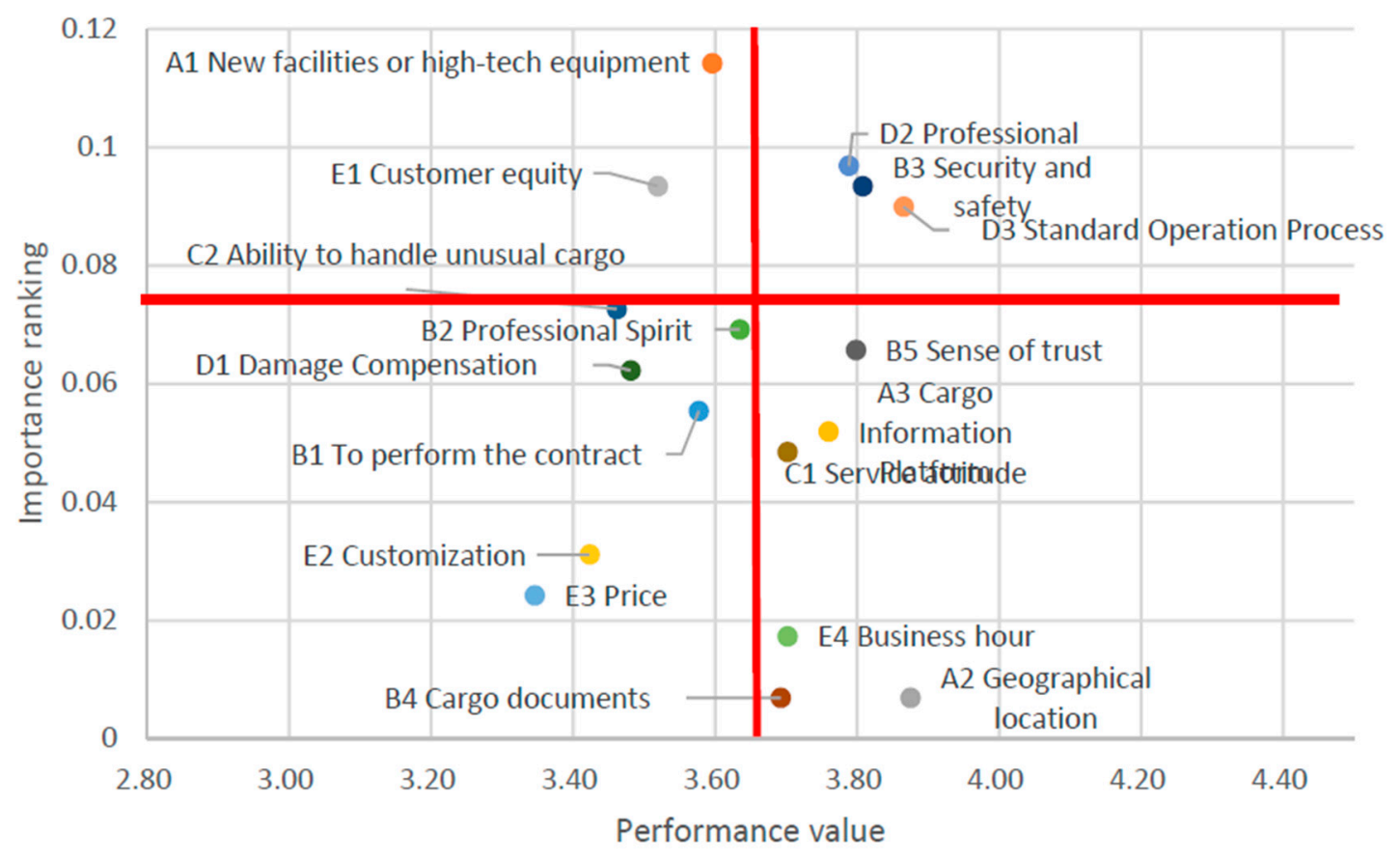

Figure 4. IPA for evaluation criteria.

The upper left grid accounts for top executive support, funding and budgets and air cargo terminals must strive to improve these areas of performance. Ignoring areas such as New facilities or high-tech equipment (A1), Customer equity (E1), Ability to handle unusual cargo (C2) and Professional spirit (B2) would pose a serious threat to the operations of the air cargo terminal.

In addition, resources that are committed to criteria located within the lower right grid would be better deployed elsewhere and it is unnecessary to focus further efforts on such resources, such as the cargo information platform (A3), for example.

Based on the total influence matrix, a causal diagram such as that illustrated in Figure 5 reveals that the air cargo terminal should increase performance in the areas of 'New facilities or high-tech equipment' (A1) and 'Professional' (D2) in order to improve the quality of service provided by the air cargo terminal and address other key factors.

Moreover, it is quite reasonable to select A1 and D2 as the starting point, since these areas are categorized as 'cause.' Effective improvements in the areas of A1 and D2 would require that air cargo terminal management strive to enhance executive functioning within air cargo terminal service quality by allocating funding and resources and eliminating obstacles.

Figure 5 shows the mutual influence found between A1 and D2, such that, in the long-run, sufficient annual funding and budget planning are necessary in order to enhance the forwarders' awareness of improving the service quality of the air cargo terminal. 


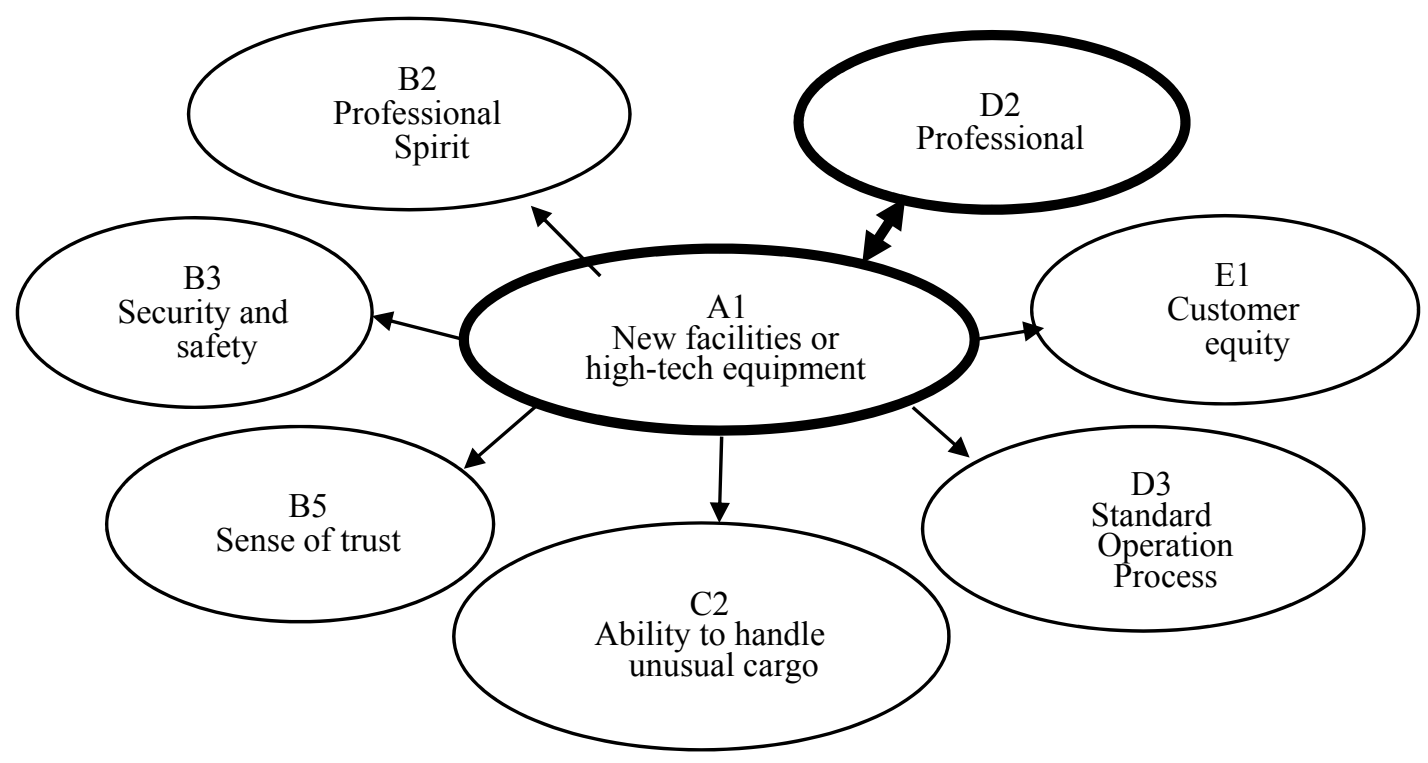

Figure 5. The causal diagram for criteria.

\subsection{SWOT Analysis}

Proposals to improve company strategy generate different levels of support and popularity over time. SWOT (Strengths, Weaknesses, Opportunities and Threats) analysis is the most popular strategic assessment utilized. When the company has good management communication within both its internal and external environment, it is more likely to perform well. However, despite their importance, many companies have often only vague ideas of their competitive strengths and weaknesses. This study used a hybrid method for improving the usability of SWOT analysis. DANP was employed to evaluate the strengths and weaknesses of the company's service quality and PEST, the most popular analytic tool, was used to assess the external environment in order to explore external opportunities and threats. Both DANP and PEST can be utilized to identify internal strengths and weaknesses as well as external opportunities and threats. The SWOT matrix can then be employed to propose strategies that are conducive to the company's sustainable competitiveness.

This study uses the PEST analysis model [24] to evaluate the politics of the air cargo terminal (for example, political-rental tax policy, labor laws, environmental regulations, trade restrictions, tariffs and political stability), economic factors (i.e., economic growth, interest rates, exchange rates and inflation rates), societal factors (i.e., social-cultural perspectives, health awareness, population growth rates, age structure, work attitudes and safety requirements) and technological factors (i.e., technological-R\&D activities, automation, technological incentives and technological development) in order to understand current market growth, company status, future development potential and business direction, as shown in Table 9 below.

Based on the advantages and disadvantages outlined above as well as on the external environment analysis illustrated in Table 2, Table 10 unifies the SWOT Matrix for the air cargo terminal. The Strategy matrix aimed to improve air cargo terminal services and sustainable competitiveness and yielded 11 strategic suggestions which are outlined as follows:

Strategy 1 (SO1) - Utilize the government's development of the New South-Oriented Policy to enhance overall operating performance: Following the government's New South-Oriented Policy, the company should harness its professional capabilities and capitalize on its advantageous position as an official promoter in order to open new export routes.

Strategy 2 (SO2)-Exploit geographical advantage in order to compete in the cross-border e-commerce market: With changes in consumer behavior, rapid growth in the demand for logistics 
of goods, rise of cross-border e-commerce with prompt delivery times, as well as its geographical advantage, Taiwan can better seize compete in the cross-border e-commerce market.

Strategy 3 (SO3) - Cooperate to promote the Sea-Air Transport Plan to seize the cross-border e-commerce market: The Free Trade Port and the Taipei Port are geographically close. The Taiwan Port Company and the Taoyuan Airport Company have cooperated to promote the Sea-Air Transport Plan and cross-border e-commerce goods from neighboring countries. These companies use sea/air couriers to transport goods within Taiwan and operate via sea/air for international imports/exports in order to ensure that e-commerce goods can benefit from the most optimal time schedules and attract more cross-border e-commerce cooperation.

Strategy 4 (SO4)-Actively invest in cold chain certification for higher unit price of temperature-control products: temperature-control products are familiar with operations requiring temperature control. In entering the cold chain market where environmental control is more stringent, its advantages of professional and standard operation processes can help it enter the cold chain market faster than other warehouses. It actively invests in the cold-chain market and strive for higher-priced temperature-control products to make up for the volume of aircraft inventory that may be lost in the future.

Strategy 5 (WO1) - Improve the Taoyuan Aerotropolis Project's investment into warehouses: Based on the current plan announced by the Taoyuan Aerotropolis Project, a specific area will be designated as a cargo area for the airport. In the meantime, new automation of storage and transportation equipment systems can be introduced, which will improve the efficiency of air cargo handling, address the problem of modernization and improve cargo security.

Strategy 6 (WO2)-Use the "Maritime and Aviation Training Fund" to improve the quality of talent: use the "Sea and Air Talent Training Fund" launched by the government in 2014 to plan talent training and development, expand the talent pool and improve the professional of its service.

Strategy 7 (ST1) - Reduce operating costs by reviewing professional and standard operating procedures: Take advantage of its experienced and mature management style and emergency processing capabilities to reduce operating costs and increase overall profitability by reviewing professional and standard operating procedures.

Strategy 8 (ST2)-Use the airline alliance to improve the transit of goods: Utilize the team to cooperate with other teams and harness their own professional and standardized operating processes to strive for a higher volume of re-transit goods, increase the volume of goods and reduce the impact of reduced export volume.

Strategy 9 (ST3) - Work with business partners for the integration of additional international air cargo: Warehouses can cooperate with business partners, utilizing advantages such as its professional and its security and standard operating procedures, so as to integrate more international air cargo.

Strategy 10 (WT1) - Strengthen the spirit of professional service among employees to improve customer satisfaction: As air cargo terminals have always operated within an oligopoly market, less emphasis has been placed on talent training, which resulted in poor professional performance. By developing staff education and training opportunities and investing in talent resources, it was proposed that customer satisfaction can be improved, thereby consolidating sources of supply.

Strategy 11 (WT2) - It is suggested that the automated delivery system should be developed to promote customer rights and interests: goods require a substantial manual identification due to the transfer of goods from sea to air and vice versa. Therefore, the prompt delivery of goods is sometimes not possible and the customer's needs cannot be met, which thus poses implications for the customer's rights and interests. As such, it is recommended that an automated delivery system be developed to expedite the process of goods separation, identification and classification so as to improve the rights and interests of customers. 
Table 9. PEST analysis.

\begin{tabular}{|c|c|}
\hline PEST Factors & External Environment \\
\hline Politics & $\begin{array}{l}\text { Political influence on trade-China (including Hong Kong and Macao) is the largest area that receives freight transport from } \\
\text { Taoyuan Airport, accounting for } 1 / 3 \text { of the total cargo volume transported via the airport. Political relations between Taiwan } \\
\text { and China has the greatest influence on bilateral trade. } \\
\text { Promotion of the Free Trade Port Policy-The "Challenge } 2008 \text { National Development Priority Plan" was put forward in } 2002 \\
\text { by the Executive Yuan, which includes one of the subprograms, "Planning for Free Trade Port Area," in order to tie in with } \\
\text { changes to the global operational model of the industry and to use domestic and foreign customs. To attract multinational } \\
\text { corporations and Taiwanese business people to perform value-added operations or various business activities in the port area. } \\
\text { New South-Oriented Policy-The "New South-Oriented Policy" adopted in the "Foreign Economic and Trade Strategic Talks" } \\
\text { in } 2016 \text { will promote the establishment of regional "economic community awareness" by establishing mutually beneficial } \\
\text { economic and trade relations with Southeast Asian and South Asian neighboring countries. } \\
\text { Taoyuan Aerotropolis Plan-"International Airport Park Development Ordinance" was published in January 23, 2009. } \\
\text { In 2014, the government launched the "Maritime and Air Transport Talent Training Fund," which aimed to support talent } \\
\text { training, as well as development within the shipping and aviation industries, in order to expand the talent pool and support the } \\
\text { long-term sustainable development of both industries. }\end{array}$ \\
\hline Economy & $\begin{array}{l}\text { The growth of the global pharmaceutical market-There has been an increase in air demand for medical supplies and airlifting } \\
\text { of biotechnological and medical supplies, which will reach USD1.12 trillion by } 2022 \text {. } \\
\text { Change of order and delivery mode-In the past, the exportation of key components from Taiwan adopted a model whereby } \\
\text { shipping took place from Taiwan, manufacturing was carried out in Mainland China and goods were exported from Taiwan, } \\
\text { thus boosting Taiwan's import/export business. Today, with the relocation of Taiwanese manufacturers, increasingly more } \\
\text { products are shipped and exported directly from China or overseas. The pattern of delivery orders as seen in Taiwan in the past } \\
\text { has disappeared. Instead, more and more orders are placed in Taiwan and goods are exported overseas. }\end{array}$ \\
\hline Society & $\begin{array}{l}\text { The rise of cross-border e-commerce-With the improvement of consumer consumption habits, online shoppers hope to receive } \\
\text { goods faster, which urges cross-border e-commerce to change access patterns. Goods that were once shipped by cargo ships, } \\
\text { trains and trucks have been increasingly transported by air. Consumer acceptance of higher prices has increased and basic daily } \\
\text { necessities such as dog food and pasta sauce have now begun to be transported by air. }\end{array}$ \\
\hline Technology & $\begin{array}{l}\text { Progress in packaging and planting technology for agricultural flowers-Developments in packaging and planting technology } \\
\text { for highly priced agri-flowers and so forth, has effectively reduced marine transportation losses and diminished the dependency } \\
\text { on air transport. }\end{array}$ \\
\hline
\end{tabular}

Table 10. Strategy matrix proposed to improve air cargo terminal services and sustainable competitiveness.

\begin{tabular}{|c|c|c|}
\hline & Strengths (S) & Weaknesses (W) \\
\hline Strategy Environment & $\begin{array}{l}\text { S1: Professional }(D 2) \\
\text { S2: Security and Safety (B3) } \\
\text { S3: Standard Operation } \\
\text { Processes (D3) } \\
\text { S4: Sense of Trust (B5) }\end{array}$ & $\begin{array}{l}\text { W1: New Facilities or High-Tech } \\
\text { Equipment (A1) } \\
\text { W2: Customer Equity (E1) } \\
\text { W3: Ability to Handle Unusual Cargo } \\
\text { (C2) } \\
\text { W4: Professional Spirit (B2) }\end{array}$ \\
\hline Opportunities $(\mathrm{O})$ & SO Strategy & WO Strategy \\
\hline $\begin{array}{l}\text { O1: Government's } \\
\text { development of the New } \\
\text { South-Oriented Policy } \\
\text { O2: Rise of cross-border e- } \\
\text { commerce } \\
\text { O3: Taoyuan aviation city } \\
\text { plan } \\
\text { O4: Promotion of the Free } \\
\text { Trade Port Policy } \\
\text { O5: Global } \\
\text { pharmaceutical market } \\
\text { growth } \\
\text { O6: Maritime and air } \\
\text { transport talent training } \\
\text { fund }\end{array}$ & $\begin{array}{l}\text { (SO1)-Utilize the government's } \\
\text { development of the New South- } \\
\text { Oriented Policy to enhance } \\
\text { overall operating performance. } \\
\text { (SO2)-Use geographical } \\
\text { advantage to occupy the cross- } \\
\text { border e-commerce market. } \\
\text { (SO3)-Cooperate to promote } \\
\text { the Sea-Air Transport Plan to } \\
\text { compete in the cross-border e- } \\
\text { commerce market } \\
\text { (SO4)-Compete in the cold- } \\
\text { chain market }\end{array}$ & $\begin{array}{l}\text { (WO1)-Make use of the Taoyuan } \\
\text { aviation city plan to improve air cargo } \\
\text { terminals facilities. } \\
\text { (WO2)-Enhance the quality of talent } \\
\text { using the "Maritime and Aviation } \\
\text { Training Fund" }\end{array}$ \\
\hline Threats $(\mathrm{T})$ & ST Strategy & WT Strategy \\
\hline $\begin{array}{l}\text { T1: Political impact on } \\
\text { trade } \\
\text { T2: Changes in exporters' } \\
\text { order-delivery mode } \\
\text { T3: Improvement in } \\
\text { agricultural flower } \\
\text { packaging and planting } \\
\text { technology }\end{array}$ & $\begin{array}{l}\text { (ST1)-Reduce operating costs } \\
\text { through professional and } \\
\text { standard operating procedures. } \\
\text { (ST2)-Use the airline alliance to } \\
\text { increase the volume of re- } \\
\text { exports. } \\
\text { (ST3)-Collaborate with } \\
\text { business partners to integrate } \\
\text { more international air cargo. }\end{array}$ & $\begin{array}{l}\text { (WT1) - Enhance employees' } \\
\text { professional service spirit for higher } \\
\text { customer satisfaction. } \\
\text { (WT2) - Build an automated delivery } \\
\text { system to increase customer equity }\end{array}$ \\
\hline
\end{tabular}

\section{Conclusions}

This article focuses on the quality of service provided by the air cargo terminal business from the perspective of the customer-contractor relationship and identifies eight key attributes, namely, 'New facilities or high-tech equipment,' 'Professional, 'Security and safety,' 'Reliability,' 'Ability to 
handle unusual cargo,' 'Professional spirit,', 'Standard operation processes,' and 'Customer equity' which represent critical factors that influence the service quality of air cargo terminals. Strategic recommendations are proposed based on a SWOT cross-analysis of the external environment and the specific advantages and disadvantages of the operational practices adopted by air cargo terminals. Based on causality analysis and industry interviews, the study recommends that air cargo terminals place emphasis on "Professional" as a key criterion in order to optimize service quality.

This study developed a research framework for improving the service quality of air cargo terminals using the Delphi method and the Decision-making Laboratory and Network Analysis methodology to highlight the causal relationship between the key attributes and the criteria with respect to the 'quality of service' and improvement of sources. Faced with fierce market competition, the results of this study offer a framework for air cargo terminals to improve the quality of the service with limited resources and enhance the performance of overall service quality by implementing changes at the source-level. By optimizing the key attributes, resources can be deployed more effectively and the air cargo terminal can enjoy a more sustainable competitive advantage.

Author Contributions: Y.-C.H. and P.-C.L. conceived the research; P.-C.L. and Y.-S.C. collected and analyzed data, and performed the experiments; Y.-C.H. and P.-C.L. wrote the paper; and Y.-J.C. revised the paper. All authors have read and approved the final version.

Funding: This research is partially supported by the Ministry of Science and Technology, Taiwan under grant MOST 106-2410-H-033-006-MY2.

Acknowledgments: The authors would like to thank the anonymous referees for their valuable comments.

Conflicts of Interest: The authors declare no conflict of interest.

\section{References}

1. Boeing. World Air Cargo Forecast 2016-2017. Available online: http://www.boeing.com/resources/ boeingdotcom/commercial/about-our-market/cargo-market-detail-wacf/download-report/assets/ pdfs / wacf.pdf (accessed on 3 July 2018).

2. IATA. Another Strong Year for Airline Profits in 2017; IATA: Montreal, QC, Canada, 2016.

3. Taiwan Industry Economics Services. Air Cargo Industry Basic Information. Available online: https: / / tie.tier.org.tw / db /article/list.asp?code=IND30-14\&ind_type=midind (accessed on 3 July 2018).

4. Parasuraman, A.; Zeithaml, V.A.; Berry, L.L. Servqual: A multiple-item scale for measuring consumer perceptions of service quality. Retail. Crit. Concepts 1988, 64, 12-40.

5. Taiwan. Clause 16, article 2 of the civil aviation law of Taiwan. 2018.

6. Hu, K.-C.; Lu, L.M.; Huang, M.-C. The effects of service quality, innovation capability, and corporate image of air cargo terminals on customer satisfaction and loyalty. Int. J. Oper. Res. 2010, 2, 037-054.

7. Chao, C.-C.; Huang, C.-C.; Yeh, T.-L. Market segmentation of air cargo terminal in taiwan. Marit. Q. 2012, 21, 45-70.

8. Parasuraman, A.; Zeithaml, V.A.; Berry, L.L. A conceptual model of service quality and its implications for future research. J. Mark. 1985, 49, 41-50. [CrossRef]

9. Park, Y.; Choi, J.K.; Zhang, A. Evaluating competitiveness of air cargo express services. Transp. Res. Part E Logist. Transp. Rev. 2009, 45, 321-334. [CrossRef]

10. Chu, H.-C. Exploring preference heterogeneity of air freight forwarders in the choices of carriers and routes. J. Air Transp. Manag. 2014, 37, 45-52. [CrossRef]

11. Chang, S.-C. The effects of air cargo warehouses' service quality on trust, commitment and behavioral intentions. Logist. Res. Rev. 2007, 6, 41-55.

12. Wang, R.-T. Improving service quality using quality function deployment: The air cargo sector of china airlines. J. Air Transp. Manag. 2007, 13, 221-228. [CrossRef]

13. Huang, S.-H.S.; Tseng, W.-J.; Hsu, W.-K.K. An assessment of knowledge gap in service quality for air freight carriers. Transp. Policy 2016, 50, 87-94. [CrossRef]

14. Meng, S.-M.; Liang, G.-S.; Lin, K.; Chen, S.-Y. Criteria for services of air cargo logistics providers: How do they relate to client satisfaction? J. Air Transp. Manag. 2010, 16, 284-286. [CrossRef] 
15. Lin, J.-F. The Service Quality of Airline Cargo Transportation-A Case Study of Eva Air; National Taiwan Ocean University: Kaohsiung City, Taiwan, 2010.

16. Hsu, W.-K.K. A gap analysis in service quality for air freight forwarders. J. Chin. Inst. Transp. 2011, 23, 515-540. [CrossRef]

17. Yoon, S.-H.; Park, J.-W. A study of the competitiveness of airline cargo services departing from korea: Focusing on the main export routes. J. Air Transp. Manag. 2015, 42, 232-238. [CrossRef]

18. Pill, J. The delphi method: Substance, context, a critique and an annotated bibliography. Socio-Econ. Plan. Sci. 1971, 5, 57-71. [CrossRef]

19. Dalkey, N.; Helmer, O. An experimental application of the delphi method to the use of experts. Manag. Sci. 1963, 9, 458-467. [CrossRef]

20. Saaty, T.L. The analytic hierarchy and analytic network measurement processes: Applications to decisions under risk. Eur. J. Pure Appl. Math. 2008, 1, 122-196.

21. Hu, Y.-C.; Chiu, Y.-J.; Hsu, C.-S.; Chang, Y.-Y. Identifying key factors for introducing gps-based fleet management systems to the logistics industry. Math. Probl. Eng. 2015, 2015, 1-14. [CrossRef]

22. McLean, I. Condorcet: Foundations of Social Choice and Political Theory; Edward Elgar Publishing: Cheltenham, UK, 1994.

23. Martilla, J.A.; James, J.C. Importance-performance analysis. J. Mark. 1977, 41, 77-79. [CrossRef]

24. Aguilar, F.J. Scanning the Business Environment; Macmillan: New York, NY, USA, 1967.

(C) 2018 by the authors. Licensee MDPI, Basel, Switzerland. This article is an open access article distributed under the terms and conditions of the Creative Commons Attribution (CC BY) license (http://creativecommons.org/licenses/by/4.0/). 